\title{
Nachruf auf Dr. Helga Pense
}

Geb. 23. Juli 1936 in Stuttgart, gest. 8. August 2013 in Frankfurt a.M.

Der djb trauert um sein langjähriges Mitglied Rechtsanwältin und Notarin a.D. Dr. Helga Pense. Sie starb am 8. August 2013 kurz nach Vollendung ihres 77. Geburtstags.

Dr. Helga Pense studierte in Mainz und Freiburg und promovierte 1961 an der Universität Basel. Sie heiratete 1964 einen Juristen, 1965 gründeten sie die Kanzlei Pense Rechtsanwälte. Aus der Ehe gingen drei Söhne hervor, von denen zwei ebenfalls Juristen wurden, die nun die Kanzlei weiterführen.

Dr. Helga Pense war eine vielseitige Juristin und eine versierte Fachanwältin für Familienrecht. Getreu ihrer Einstellung, dass Frauen mehr Präsenz zeigen und Aufgaben übernehmen sollten, arbeitete sie im Fachausschuss Familienrecht der Rechtsanwaltskammer Frankfurt, bis zuletzt als Vorsitzende, in der Vertreterkammer des Versorgungswerks der Rechtsanwälte im Land Hessen und in der Satzungsversammlung der Bundesrechtsanwaltskammer mit. Der Besuch von Fachveranstaltungen, insbesondere des Deutschen Familiengerichtstags und des Deutschen Juristentags waren ihr wichtig.

Im djb hat sich Dr. Helga Pense in den 46 Jahren ihrer Mitgliedschaft aktiv eingebracht und in vielfältiger Weise für die Ziele des djb engagiert. Ihr regionaler Einsatz führte sie von 1992 bis 1994 in den Vorstand der Untergruppe Rhein-Main und von 1994 bis 1997 in den Vorstand der Landesgruppe Hessen. Dem Familien- und Erbrecht galt ihr besonderes Interesse. Mit ihren Fachkenntnissen hat sie über Jahre hinweg die Tätigkeit verschiedener Kommissionen und Arbeitsstäbe des djb mitgestaltet. Von 2001 an gehörte sie der Kommission Zivil-, Familien- und Erbrecht, Recht anderer Lebensgemeinschaften an. Dr. Helga Pense hat ihren Sachverstand und ihre Erfahrung eingebracht und stets darauf hingewirkt, dass bei der Fortentwicklung des Familienrechts auch die materiellen

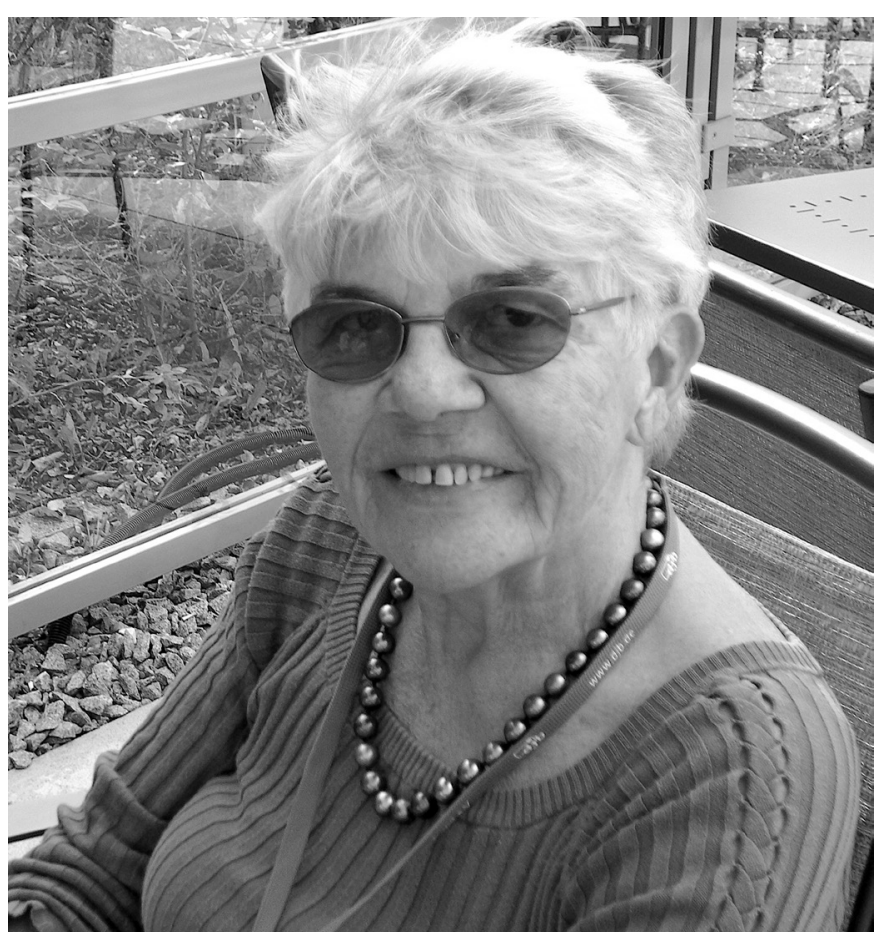

Interessen der Frauen beim Unterhalt, Versorgungsausgleich und im Güterrecht nicht zu kurz kommen. Zur Ausarbeitung inhaltlicher Stellungnahmen gab sie wertvolle Impulse. Für die Mitglieder der Kommission war Dr. Helga Pense stets eine kompetente Ansprechpartnerin; die Zusammenarbeit mit ihr war von Vertrauen und Kollegialität geprägt.

Mit Helga Pense verliert der djb eine kluge und kundige Rechtsanwältin. Wir vermissen sie.

\section{Brigitte Meyer-Wehage, Ingrid Baer und Barbara Helfert}

(für die Kommission Zivil-, Familien- und Erbrecht, Recht anderer Lebensgemeinschaften)

\section{Nachruf auf Dr. Ulrike Guckes}

\section{Geb. 29. März 1978, gest. 10. September 2013}

Der djb trauert um sein Mitglied Rechtsanwältin Dr. Ulrike Guckes. Sie starb am 10. September 2013 mit nur 35 Jahren nach langer schwerer Krankheit und hinterlässt Mann und Kind.

Dr. Ulrike Guckes studierte Rechtswissenschaften an der Universität Potsdam und absolvierte ihr Referendariat in Berlin. 2007 promovierte sie an der Humboldt-Universität zu Berlin mit einer Arbeit zur „Opferentschädigung nach zweierlei Maß? Eine vergleichende Untersuchung der gesetzlichen Grundlagen der Entschädigung für das Unrecht der NS-Diktatur und der SED-Diktatur“.
2007 wurde sie Rechtsanwältin und Geschäftsführerin beim Deutschen Anwaltverein. Sie war als Geschäftsführerin und Mitglied der Hauptgeschäftsführung des Deutschen Anwaltvereins für Aus- und Weiterbildung zuständig.

Sie trat erst 2011 dem djb als Mitglied bei. Doch auch schon in den Jahren davor habe ich sie als stets hilfsbereite und engagierte Kollegin und Ansprechpartnerin im DAV kennen gelernt. Auch der djb wird sie vermissen.

\section{Anke Gimbal \\ Geschäftsführerin djb, Berlin}

